\title{
Serum MDA and Vitamin C level in Conversion Disorder Patients
}

\section{Rubaba Karim ${ }^{1}$, Zabun Nahar ${ }^{2}$, Mohammad Safiqul Islam², Maizbha Uddin Ahmed $^{2}$, AGM Mustafa' ${ }^{2}$, Md. Hasanuzzaman Shohag ${ }^{2}$, Abdullah Al Maruf ${ }^{2}$, and Abul Hasnat ${ }^{2}$}

\author{
${ }^{1}$ Department of Pharmacy, University of Asia Pacific, Dhanmondi, Dhaka-1209, Bangladesh \\ ${ }^{2}$ Department of Clinical Pharmacy and Pharmacology, Faculty of Pharmacy, University of Dhaka, \\ Dhaka-1000, Bangladesh
}

\begin{abstract}
In the present study serum Malondialdehyde (MDA) and Vitamin C profiles of conversion disorder patients were compared with control and evaluated the correlation between MDA and vitamin C level was evaluated with their socioeconomic factors. Conversion disorder patients $(n=45)$, age ranging from 17 to 41 years, were randomly recruited from the Department of Psychiatry, Bangabandhu Sheikh Mujib Medical University Hospital, Dhaka, Bangladesh for this study. Control group also included 45 healthy individuals matched by the socio-demographic status to that of the patients. Blood samples were analyzed for determining MDA and vitamin C using Ultraviolet-Visible (UV-VIS) spectroscopy. Serum concentrations of MDA and vitamin C of conversion disorder patients were $2.19 \pm 1.47$ and $19.23 \pm 5.59 \mu \mathrm{mol} / \mathrm{L}$ respectively while these were $2.11 \pm 0.88$ and 21.00 $\pm 4.96 \mu \mathrm{mol} / \mathrm{L}$ in control subjects respectively. Socioeconomic data revealed that most of the patients were young female and unmarried. The mean BMI of patients $(21.05 \pm 3.39)$ were not significantly different $(\mathrm{P}>0.05)$ from the control subjects $(20.86 \pm 1.86)$. Moreover, statistical analysis revealed that there were no significant correlation between MDA, vitamin C concentrations and socioeconomic factors. The results of our study have shown higher oxygen free radical production, evidenced by increased levels of MDA and decreased levels of ascorbic acid which supports the oxidative stress in conversion disorder patients.
\end{abstract}

Key words: Conversion disorder patients, MDA, vitamin C, socio-economic status

\section{INTRODUCTION}

Conversion disorder is the apparent dysfunction of sensory and motor systems consistent with psychological conflicts and psychosocial stressors. ${ }^{1}$ In DSM-IV, it is considered as a kind of somatoform disorder and DSM-IV diagnostic system includes somatization disorder and conversion disorder in the same group of illness. ${ }^{2}$ The conversion disorders are classified as dissociative disorder and named as dissociative motor disorders, dissociative convulsions, dissociative anesthesia and sensory loss and mixed dissociative disorders in ICD-10. ${ }^{3}$ Spitzer et $a{ }^{(4)}$ reported that dissociative symptoms are more

Correspondence to: Dr. Abul Hasnat

Tell: +88-02-9667850; Fax No: +88-02-8615583

Email: ahasnat99@yahoo.com

Dhaka Univ. J. Pharm. Sci. 10(1): 59-64, 2011 (June) frequent in patients with conversion disorder, whereas general psychopathology is as common as that in other psychiatric conditions. ${ }^{4}$ Conversion disorder is a specific form of somatization in which the patient presents with symptoms and signs that are confined to the voluntary central nervous system. ${ }^{5}$ The disorder's basis is believed to be the substitution of a physical symptom for an emotional conflict that cannot be expressed openly. ${ }^{6}$

Psychogenic dementia as well as loss of speech and language or a disturbance of any of the special senses may be observed by conversion disorder patients. ${ }^{7,8}$ This reflects the fact that the neurologic presentation is ideogenic and derives from patient beliefs about how neurologic symptoms should present. The patient applies this belief consciously to 
govern behavior, resulting in bizarre, atypical, and non-organic findings on neurologic examination. About 3\% of mental health clinic referrals are due to Conversion disorder. ${ }^{5}$ Conversion disorder is more likely to develop among older adolescents or young adults, women, and people from lower socioeconomic classes.

'Hysteria' (Conversion disorder) was originally understood to be a condition exclusively affecting women, though it has increasingly been recognised in men. ${ }^{9}$ In recent studies, women continue to predominate, with between 2 and 6 female patients for every male. ${ }^{9,10}$ Other studies suggest that the symptoms are most common in young women ${ }^{1}$, rare in children under 8 years old, more common in rural areas, among uneducated people, and in the lower socio economic classes. ${ }^{11}$

Oxidative stress and free radicals (FR) induced toxicity have been implicated in the pathogenesis of various neuropsychiatric disorders. ${ }^{12-14}$ Normal cellular metabolism, lipid peroxidation, activation of phagocytes, electron transport system in mitochondria, and exposure to ultraviolet (UV) light, cigarette smoke, and pollutants produce free radicals in the human body. ${ }^{15}$ Determination of level of free radicals is difficult, since they have a relatively short half-life with an extremely high reactivity. However, free radical induced damage may be prevented or alleviated by the presence of antioxidant molecules. ${ }^{16-17}$

Therefore activity of free radicals in the human body can be examined indirectly by the measurement of some antioxidant enzymes (SOD, catalase, or glutathione peroxidase), antioxidant vitamins (Vitamin E, C, A), transition metals (copper, zinc, and iron), by-products. Malondialdehyde (MDA), a naturally occurring end product of membrane lipid peroxidation, is one of the most frequently used biomarker for free radical mediated damage. ${ }^{18,19}$

Vitamins C, nonenzymatic antioxidant structure is essential for neurological antioxidant and neuroprotective function. Several studies showed that vitamin $\mathrm{C}$ is important for the central nervous system and a decrease in their concentrations causes structural and functional damage to the cells. ${ }^{20-21}$

These observations suggest that alterations in MDA and vitamin $C$ may play a role in the pathogenesis of conversion disorder. As no work has been reported regarding in MDA and vitamin $\mathrm{C}$ levels in Bangladeshi conversion disorder patients, the serum levels of MDA and vitamin $\mathrm{C}$ were determined in our study. The correlation between MDA, vitamin $\mathrm{C}$ in conversion disorder patients with different socio-demographic factors was also investigated.

\section{METHODS}

Subjects and study design. The study was conducted in the Department of Psychiatry, Bangabandhu Sheikh Mujib Medical University (BSMMU) Hospital, Dhaka, Bangladesh. Forty five conversion disorder patients (12 males \& 33 females), age ranging from 17 to 41 years, were randomly recruited in this hospital.

Two specialist psychiatrists were trained in the use of Diagnostic and Statistical Manual of Psychiatry Disorders (DSM-IV, Text revision, Fourth Edition) for this study and they conducted the diagnosis and interviewed the patients with conversion disorder. The control group included 45 healthy individuals matched by age, sex, BMI, marital status, education, area of residence, smoking habit, and socio-economic status to the patient group, with no previous history of any psychiatric disorders or any medical history that can affect the outcome of the study.

All patients were evaluated clinically (history and clinical examination). Laboratory investigations: such as (1) Complete blood count: to exclude patients with anaemia, leucopenia, leucocytosis, eosinophilia or any other abnormal figures in blood count, (2) Thyroid function tests to exclude patients with increased $T_{3}$ and $T_{4}$ serum levels or to exclude patients with low serum $T_{3}$ and $T_{4}$ levels, (3) Renal function tests (blood urea and serum creatinines) to exclude patients with renal impairment, (4) Liver function tests to exclude patients with liver affection, 
especially those with high liver enzymes or those with diminished albumin levels or high globulin levels, 5) Urine and stool analysis to exclude urinary tract infection or parasitic infestations were carried out. Exclusion criteria included patients with previous diseases that can affect immunity, e.g. rheumatic fever, rheumatoid arthritis, liver diseases, renal diseases, etc.; patients under medication for mania, patients who received any other medication such as oral contraceptives, non-steroidal antiinflammatory drugs, corticosteroids, anticonvulsants, and antidepressants, or had ECT during the preceding 6 months. Patients who were mentally retarded and suffered from comorbid psychiatric disorders and/or with substance disorder were also excluded from the study.

Blood sampling and storage. $10 \mathrm{ml}$ of venous blood was drawn from each of the conversion disorder patients and the control subjects using a plastic syringe fitted with a stainless steel needle. The blood sample was collected into a sterile tube and allowed to clot at room temperature for half an hour and then centrifuged at $3000 \mathrm{rpm}$ for 15 minutes. Serum samples were stored at $-80^{\circ} \mathrm{C}$ and protected from light until analysis.

Measurement of MDA. Serum MDA levels were measured according to the modified method described by Satoh which is based on the principle that MDA, i.e., the specific product of lipid peroxidation reacts with thiobarbituric acid (TBA) to form a colored complex that gives maximum absorption at $532 \mathrm{~nm}^{22,23}$ Briefly, $0.5 \mathrm{ml}$ of serum was added to $2.5 \mathrm{ml}$ of $20 \%$ trichloroacetic acid, allowed to stand for $10 \mathrm{~min}$ at room temperature. After centrifugation at 3,500 rpm for $10 \mathrm{~min}$, the supernatant was decanted and dispersed with $2.5 \mathrm{ml}$ of $0.05 \mathrm{M}$ sulphuric acid. Then $3.0 \mathrm{ml}$ of 2thiobarbituric acid $\left(0.07 \%\right.$ in $\left.1 \mathrm{~mol} / \mathrm{l} \mathrm{Na}_{2} \mathrm{SO}_{4}\right)$ was added to this precipitate, and the coupling of lipid peroxide with TBA was carried out by heating in a boiling water bath for $30 \mathrm{~min}$. After cooling with cold water, the resulting chromogen was extracted with $4.0 \mathrm{ml}$ of n-butyl alcohol by vigorous shaking. Separation of the organic phase was facilitated by centrifugation at 3,000 rpm for $10 \mathrm{~min}$, and absorbance of the supernatant was measured spectrophotometrically (UV-1201 Spectrophotometer; Shimadzu Corporation, Japan) at $530 \mathrm{~nm}$ using 1,1,3,3-tetraethoxy-propane as standard. Thiobarbituric acid reactive substances (TBARS) were expressed as $\mu \mathrm{mol} / \mathrm{l}$.

Measurement of vitamin C. The concentration of vitamin $C$ in the serum was estimated by the phenyl-hydrazine spectrophotometry method. ${ }^{24}$ For the measurement procedure, $0.3 \mathrm{ml}$ of plasma was added to $1.2 \mathrm{ml}$ of $5 \%$ trichloroacetic acid and then centrifuged at $3000 \mathrm{rpm}$ for $10 \mathrm{~min}$. Clear supernatant of $0.96 \mathrm{ml}$ was treated with $0.4 \mathrm{ml}$ of dinitrophenylhydrazine-thiourea-copper sulphate (DTC) reagent and heated at $60^{\circ} \mathrm{C}$ for $1 \mathrm{hr}$ in a water bath. Immediately after incubation, the sample was chilled in ice-cold water and $1.6 \mathrm{ml}$ of $65 \%$ sulphuric acid solution was added gradually. The procedure was repeated with $0.3 \mathrm{ml}$ of working standard solution of ascorbic acid as well as with $0.3 \mathrm{ml}$ of reagent blank. Absorbances of sample and standard were read against reagent blank at $520 \mathrm{~nm}$ with a spectrophotometer.

Statistical analysis. Data were analyzed using SPSS software (Version 11.0) and the values were expressed as percentage, mean and standard deviation. Comparison of serum MDA and vitamin C of the patients and controls were performed by using independent $t$ test. To determine the contribution of different socio-demographic factors and BMI on the concentration levels of MDA and vitamin C Pearson's correlation analysis was carried out. All comparisons were 2-tailed, and $p$ values of $<0.05$ were considered significant.

\section{RESULTS AND DISCUSSION}

Socio-demographic data of both control subjects and conversion disorder patients are presented in Table 1 which should the prevalence (73.33\%) of female patients. The female predominance was also found in some previous studies. ${ }^{1,9,25}$ Other studies have found no difference between the sexes. ${ }^{11}$ Most of the patients are from rural area (68.89\%), had a 
secondary level of education (Figure 1) and are young (86.67\% are less than 25 years). Previous study has also found similar result where conversion disorder is more common in rural areas, among uneducated people, and in the lower socio economic classes. $^{11}$

In our study, serum MDA level of the conversion disorder patients was found to be higher in comparison with control subject, but was not statistically significant $(p>0.05)$. However, the serum vitamin $C$ level was lower in conversion disorder patients in comparison with control subject but was not statistically significant (Table 2). No significant relationship was found between the sociodemographic variables (age, income), serum MDA and vitamin $\mathrm{C}$ levels at $5 \%$ level of significance, whereas a negative correlation was found between serum vitamin $\mathrm{C}$ level and BMI (Table 3). From the calculation of ANOVA no significant relationship was found between the variables by considering the MDA and vitamin $\mathrm{C}$ as dependent variables and socio-demographic factors e.g. age, BMI, income, occupation, education, residence, and smoking habit as independent variables.

Table 1. Socio-demographic data of conversion disorder patients $(n=45)$ and control subjects $(n=45)$.

\begin{tabular}{llcc}
\hline Parameters & & No. of patients (\%) & No. of controls (\%) \\
\hline Age (year) Range: 15-38 & $<25$ years & $39(86.67 \%)$ & $36(80.0 \%)$ \\
& $>$ 25years & $6(13.33 \%)$ & $9(20.0 \%)$ \\
& Mean \pm SD & $22.06 \pm 8.33$ & $23.93 \pm 8.06$ \\
Sex & Male & $12(26.67 \%)$ & $13(28.89 \%)$ \\
Marital Status & Female & $33(73.33 \%)$ & $32(71.11 \%)$ \\
& Married & $17(37.78)$ & $15(33.33 \%)$ \\
BMI (Kg/m2) & Single & $62.22(63.33)$ & $30(66.67 \%)$ \\
& Below 25 & $43(95.56 \%)$ & $34(75.56 \%)$ \\
Smoking Status & Above 25 & $2(4.44 \%)$ & $11(24.44 \%)$ \\
& Mean \pm SD & $21.05 \pm 3.39$ & $20.86 \pm 1.86$ \\
Monthly income & Non-smoker & $39(86.67 \%)$ & $37(82.22 \%)$ \\
& Smoker & $6(13.33 \%)$ & $8(17.78 \%)$ \\
& $0-5000$ & $3(6.67 \%)$ & $1(2.22 \%)$ \\
& $5001-20000$ & $36(80 \%)$ & $38(84.45 \%)$ \\
Area of residence & $20001-30000$ & $5(11.11 \%)$ & $5(11.11 \%)$ \\
& $>30000$ & $1(2.22 \%)$ & $1(2.22 \%)$ \\
& Rural & $31(68.89 \%)$ & $35(77.78 \%)$ \\
& Urban & $6(13.33 \%)$ & $5(11.11 \%)$ \\
& Semi-Urban & $8(17.78 \%)$ & $5(11.11 \%)$ \\
\hline
\end{tabular}

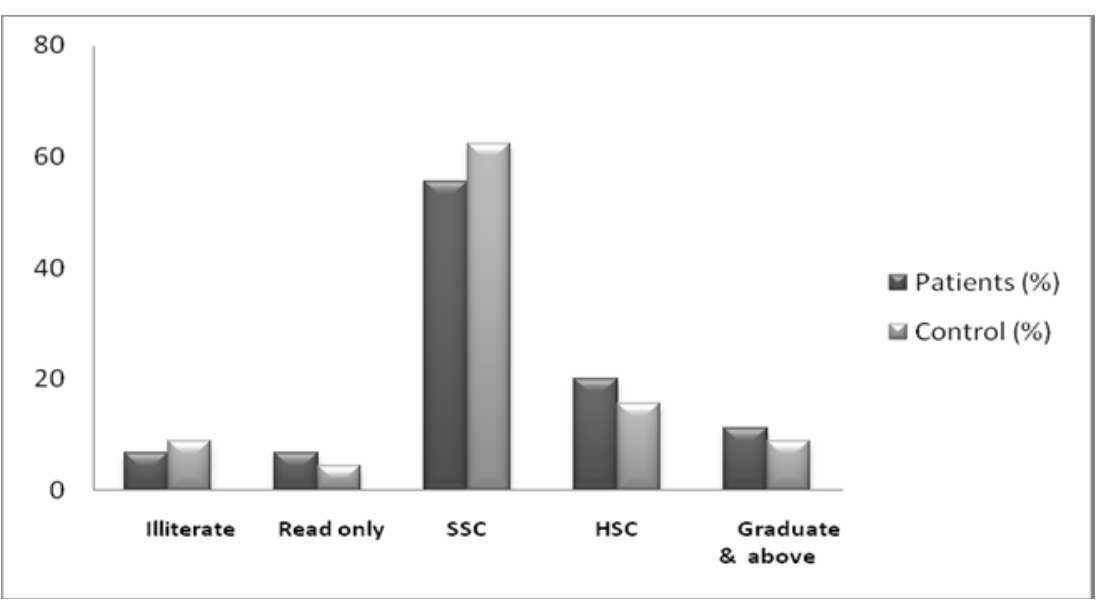

Figure 1. Education status of the Conversion disorder patients and control subjects 
Table 2. Mean serum MDA and Vitamin $C$ level of conversion disorder patients $(n=45)$ and control subjects $(n=45)$.

\begin{tabular}{lllc}
\hline & \multicolumn{3}{l}{ Mean \pm SD serum concentration } \\
\cline { 2 - 4 } & Patients & $\begin{array}{l}\text { Control } \\
\text { subjects }\end{array}$ & $p$-value \\
\hline $\begin{array}{l}\text { MDA } \\
(\mu \mathrm{mol} / \mathrm{L})\end{array}$ & $2.19 \pm 1.47$ & $2.11 \pm 0.88$ & 0.86 \\
$\begin{array}{l}\text { Vit-C } \\
(\mu \mathrm{mol} / \mathrm{L})\end{array}$ & $19.23 \pm 5.59$ & $21.00 \pm 4.96$ & 0.396 \\
\hline Independent Sample $t$-test (2-tailed): *Significance $p<0.05$
\end{tabular}

Table 3. Correlation of serum MDA, Vitamin C with BMI, income and age of conversion disorder patients.

\begin{tabular}{|l|l|l|}
\hline Parameter & MDA & Vitamin C \\
\hline Age & $r=0.328$ & $r=0.285$ \\
(Year) & $p=0.072$ & $p=0.120$ \\
\hline Income & $r=-0.089$ & $r=0.065$ \\
(BDT/month) & $p=0.634$ & $p=0.728$ \\
\hline BMI & $r=0.268$ & $r=-0.016$ \\
$\left(\mathrm{Kg} / \mathrm{m}^{2}\right)$ & $p=0.144$ & $p=0.932$ \\
\hline
\end{tabular}

Pearson's Correlation Analysis (2-tailed): "Significance, $p<0.05$.

Although, serum levels of MDA and vitamin C have been investigated in different neuropsychiatric disorders to correlate the alterations in their levels with the pathogenesis and/or progression of the disease, no study has yet been conducted to estimate the serum MDA and vitamin $\mathrm{C}$ level in the conversion disorder patients. The serum concentration of MDA was significantly higher and that of vitamin $\mathrm{C}$ was significantly lower in Schizophrenic patients. ${ }^{26}$ Similar findings were also found in obsessive-compulsive disorder ${ }^{14,27,28}$ and in panic disorder. ${ }^{29}$

\section{REFERENCE}

1. Lazare, A.1981. Current concepts in psychiatry: conversion symptoms. New Engl. J. Med. 305, 745-748.

2. American Psychiatric Association. 1994. Diagnostic and statistical manual of mental disorders. 4th ed. (DSM-IV), Washington (DC): APA.

3. World Health Organization. 1992. The ICD-10 classification of mental and behavioural disorders. Clinical descriptions and diagnostic guidelines. Geneva: World Health Organization.

4. Spitzer, C., Spelsberg, B., Grabe, H., Mundt, B., Freyberger, H.J. 1999. Dissociative experiences and psychopathology in conversion disorders. J. Psychosom. Res. 46, 291-295.
5. American Psychiatric Association. 2000. Diagnostic and statistical manual of mental disorders. 4th ed. Text revision. Washington (DC): American Psychiatric Association.

6. Deaton, A. 1998. Treating conversion disorders: Is a pediatric rehabilitation hospital the place? Rehabilitation Psychology. 43, 56-62. doi:10.1037/0090-5550.43.1.56.

7. Hurwitz, T.A. 1989. Approach to the patient with psychogenic neurological disturbance. In: Textbook of internal medicine. (Kelley, W.N., Ed.), Philadelphia: JB Lippincott Company. 2, 2518-2521.

8. Mcevoy, J., Wells, C. 1979. Case studies in neuropsychiatry II: Conversion pseudodementia. J. Clin. Psychiatry. 40, 447449.

9. Nandi, D.N., Banerjee, G., Nandi, S., et al. 1992. Is hysteria on the wane? A community survey of West Bengal, India. Br. J. Psychiatry. 160, 87-91.

10. Devinsky, O. and Fisher, R. 1996. Ethical use of placebo and provocative testing in diagnosing nonepileptic seizures. Neurology. 47, 866-870.

11. Stephansson, J.G., Messina, J.A. and Meyerowitz, S. 1976. Hysterical neurosis, conversion type: clinical and epidemiological considerations. Acta. Psychiatrica. Scandinavica. 53, 119-138.

12. Mahadik, S.P., Mukherjee, S, 1996. Free radical pathology and antioxidant defence in schizophrenia: A review. Schizophrenia Research. 19, 1-17.

13. Bilici, M., Efe, H., Koroglu, M.A., Uydu, H.A., Bekaroglu, M., Deger, O. 2001. Antioxidative enzyme activities and lipid peroxidation in major depression: Alterations by antidepressant treatments. J. Affective Disorders 64, 43-51.

14. Ersan, S., Bakir, S., Ersan. E., Dogan, O. 2006. Examination of free radical metabolism and antioxidant defence system elements in patients with OCD. Prog Neuropsychopharmacol Biol. Psychiatry. 30, 1039-42.

15. Gutteridge, J.M.C. 1995. Lipid peroxidation and antioxidants as biomarkers of tissue damage. Clin. Chem. 41, 1819-1828.

16. Cheeseman, K.H., Slater, T.F. 1993. An introduction to free radical biochemistry. Br Med Bull. 49, 481-93.

17. Butterfield, D.A., Castegna, A., Drake, J., Scapagnini, G., Calabrese, V. 2002. Vitamin E and neurodegenerative disorders associated with oxidative stress. Nutr Neurosci. 5, 229-239.

18. Janero, D.R. 1990. Malondialdehyde and thiobarbituric acid reactivity as diagnostic indices of lipid peroxidation and peroxidative tissue injury. Free Radic Biol Med. 9, 515-540.

19. Nielsen, F., Mikkelsen, B.B., Nielsen, J.B., Andersen, H.R., Grandjean, P. 1997. Plasma malondialdehyde as biomarker for oxidative stress: reference interval and effects of life-style factors. Clin Chem. 43, 1209-14. 
20. Kaplan, B.J., Crawford, S.G., Field, C.J., Simpson, J. and Steven, A. 2007. Vitamins, minerals and mood. Psychological Bulletin 133, 747-760.

21. Harrison, F.E., May, J.M. 2009. Vitamin C function in the brain: vital role of the ascorbate transporter SVCT2. Free Radical Biology \& Medicine 46, 719-730.

22. Satoh, K. 1978. Serum lipid peroxide in cerebrovascular disorders determined by a new colorimetric method. Clin Chim. Acta. 90, 37-43.

23. Yagi, K. 1984. Assay for blood plasma or serum. Methods Enzymol. 105, 328-331.

24. Lowry, H., Jeanne, A., Lopez and Otto, A. 1945. The determination of ascorbic acid in small amounts of blood serum. J. Biol. Chem. 162, 609-615

25. Carson, A.J., Ringbauer, B., Stone, J., McKenzie, L., Warlow, C. and Sharpe, M. 2000. Do medically unexplained symptoms matter? A prospective cohort study of 300 new referrals to neurology outpatient clinics. J. Neurol. Neurosurg. Psychiatry. 68, 207-10.
26. Surapaneni, K.M. 2007. Status of Lipid Peroxidation, Glutathione, Ascorbic Acid, Vitamin E and Antioxidant Enzymes in Schizophrenic Patients. J. Clin. Diag. Res. 1, 3944.

27. Ozdemir, E., Cetinkaya, S., Ersan, S., Kucukosman, S., Ersan, E.E. 2009. Serum selenium and plasma malondialdehyde levels and antioxidant enzyme activities in patients with obsessive-compulsive disorder. Progress in Neuro-Psychopharmacology \& Biological Psychiatry 33, 62-65.

28. Kuloglu, M., Atmaca, M., Tezcan, E., Gecici, O., Tunckol, H., Ustundag, B. 2002. Antioxidant enzyme activities and malondialdehyde levels in patients with obsessivecompulsive disorder. Neuropsychobiology 46, 27-32.

29. Kuloglu, M., Atmaca, M., Tezcan, E., Ustundag, B., Bulut ,S. 2002. Antioxidant enzyme and malondialdehyde levels in patients with panic disorder. Neuropsychobiology 46, 186189. 